Research Article

Vieroslav Molnár* and Katarína Lipovcová

\title{
Design of clamping structure for material flow monitor of pipe conveyors
}

https://doi.org/10.1515/eng-2019-0068

Received Aug 21, 2018; accepted Sep 15, 2019

\begin{abstract}
In terms of monitoring the material and volume flow of pipe conveyors, the conveyor is considered to be a volumetric machine that does not have a "self-defence" function - in most cases, material needs to be dosed and monitored in the critical parts of the conveyor for smooth transportation and quick detection of deficiencies and errors. Appropriate attachment of the material flow sensor to the pipe conveyor structure plays an important role for efficient material monitoring on the pipe conveyor belt. The paper specifies and subsequently analyzes selected methods of mounting an optical material flow monitor - the Bulkscan LMS511, based on the ratio index method by analyzing the advantages and disadvantages of individual variants. The optimal variant is modelled in the PTC Creo Parametric program and the estimated costs for its implementation are evaluated.
\end{abstract}

Keywords: Monitoring, sensor, security device, mounting, pipe conveyor

\section{Introduction}

The key factor of proper monitoring is the correct installation and ideal attachment of the monitoring device to the pipe conveyor construction. This is done by different handles respectively, mounting kits that provide optimal, uninterrupted and efficient monitoring. The main role is played by the design of the conveyor itself, the granularity of the material, but also the external influences.

The issue of security devices aimed at the detection of conveyed material on the conveyor belt is very complex. It

\footnotetext{
*Corresponding Author: Vieroslav Molnár: Technical University of Košice, Faculty of Manufacturing Technologies with a seat in Prešov, Bayerova 1, 08001 Prešov, Slovak Republic; Email: vieroslav.molnar@tuke.sk

Kataruna Lipovcová: Technical University of Košice, Faculty of Mining, Ecology, Process Control and Geotechnology. Letná 9, 042 00 Košice, Slovak Republic; Email: katarinalipovcova@gmail.com
}

is dealt with in two basic ways: - mechanically and optically.

There are several principles of solving the design of security devices with optical way of measuring material presence. One of them is the use of a laser beam in determining the volume, which has several practical advantages (the measurement is non-contact, the process can be optimized according to the volume, the sensor measures the actual volume on the conveyor [1, 2]). Zeng et al. [3] presented the design and verification of a mathematical model intended to measure the flow of bulk material on a belt conveyor using laser scanning technology. Transition phase speed controlled belt conveyor simulations based on an existing FEM model were discussed by He et al. [4]. Wang et al. [5] examined the lateral force of the pipe conveyor belt's vertical transport section through the selection of material diameter. Aldrich et al. [6] were engaged in research into online analysis of coal on a conveyor belt by using machine vision.

This paper specifies and subsequently analyzes the selected type of optical security device based on the ratio index method by analyzing the advantages and disadvantages of individual variants.

\section{Methods}

Pipe conveyors must have a number of safety devices installed for safe operation [7] and for protecting the conveyor belt against damage. The following can be included as security elements for the protection of the conveyor belt against damage:

- overload panels (fitted with belt scales that can be installed in a closed belt section of a pipe conveyor and are specifically designed to be used in a pipe conveyor),

- material flow monitors with vertical opening (Figure 1), with horizontal opening (Figure 2) (most often consisting of one or two doors that open when the conveyor belt is congested, while the attached position sensor detects this change and sends a signal for stopping the pipe conveyor)

ə Open Access. (C 2019 V. Molnár and K. Lipovcová, published by De Gruyter. 


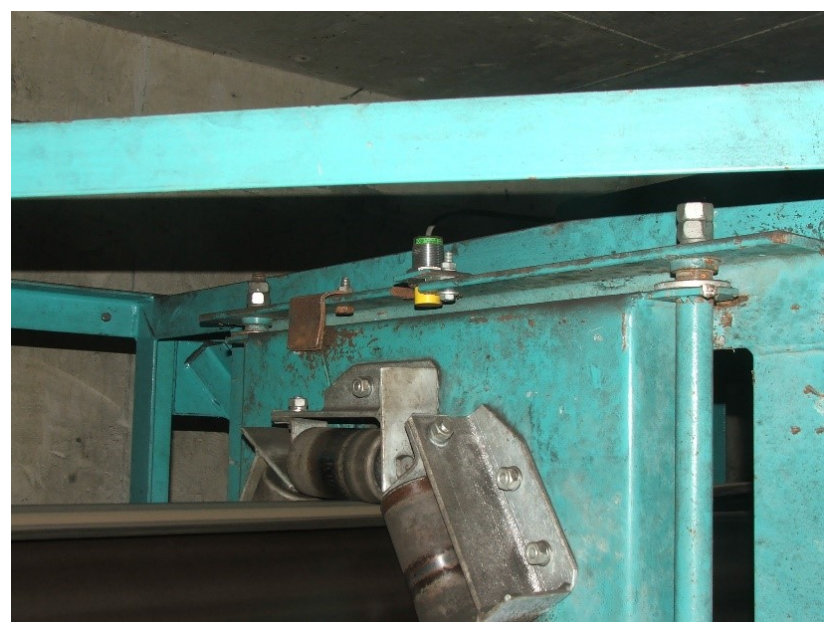

Figure 1: Material flow monitor with vertical opening [8]
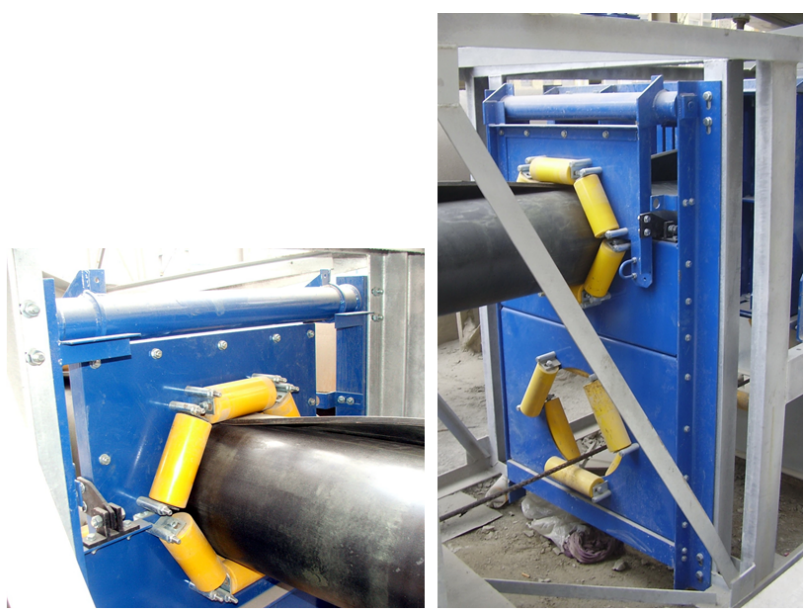

Figure 2: Material flow monitor with horizontal opening [8]

- electromagnetic devices to remove metal particles from the conveyor belt (Figure 3),

- speed sensors on the feed end drum of the pipe conveyor,

- sensors of correct direction resp. belt breakage,

- emergency conveyor shut-off cable (stretched along the footbridge along the conveyor side),

- clogging (blockage) dump chute sensors (Figure 4).

The optical flow monitor of the clogging (blocking) of the dump chute is shown in Figure 4, where the raw material is transported by means of a conveyor belt from a landfill to a shredder or a transfer point. Mineral volume is measured optically at the inlet to the crusher. This optimizes the capacity and reduces the filling time. The optical sensor ensures contactless recording of volume flow on conveyor belts by means of laser beam flight time measurement technology. The optical monitor is characterized by its robustness, reliability and wear resistance. Thanks

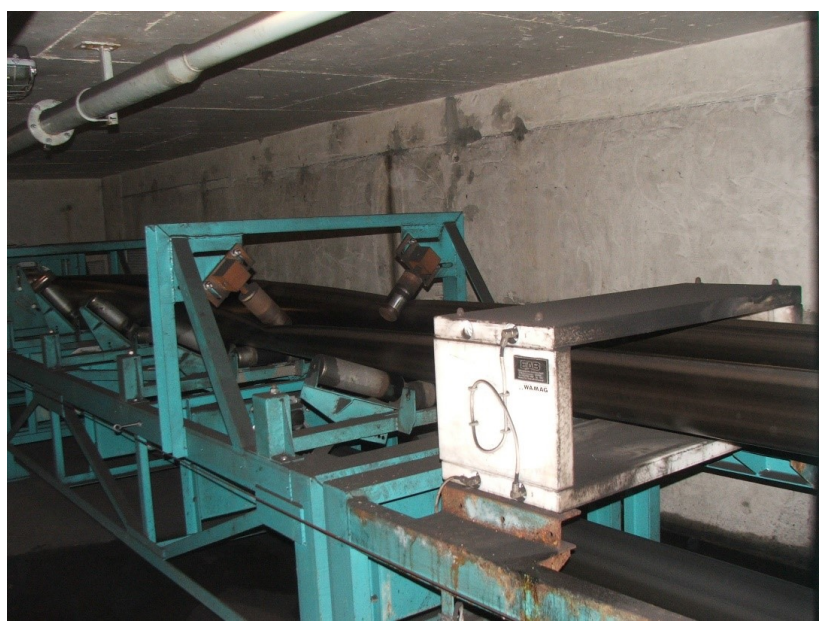

Figure 3: Electromagnetic device for removing metallic particles [8]

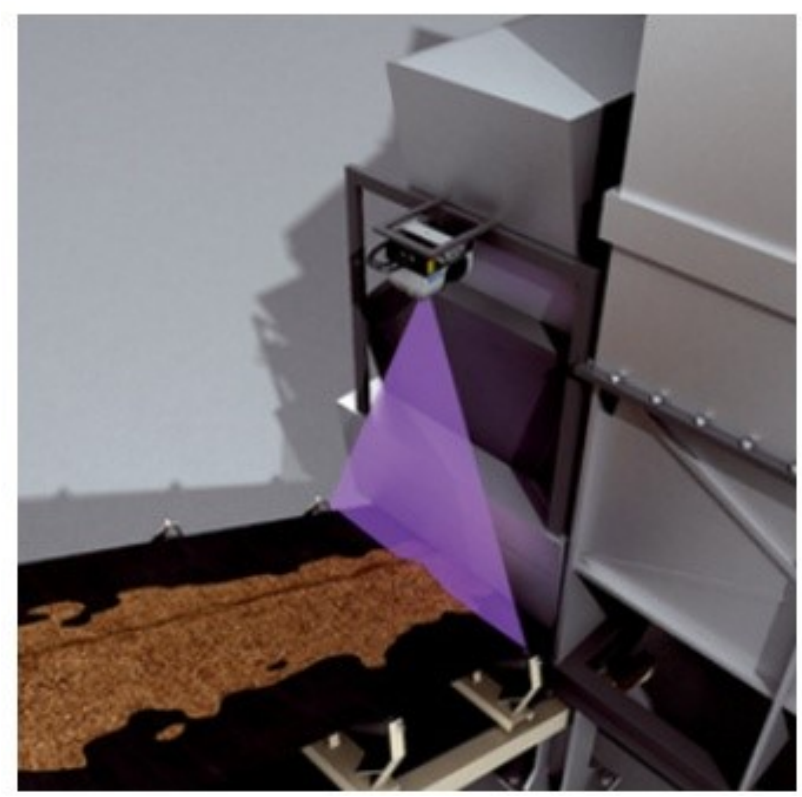

Figure 4: Optical flow crusher monitor and conveyor belt tracking [9]

to the integrated centre of gravity calculation system it enables to maximize the transport performance and detect unilateral or uneven load on the conveyor belt.

Benefits include lower belt wear and lower maintenance costs [9]. Optical flow monitors can be used not only on conveyor belts, but also on other devices that require inspection, recording, measurement and monitoring. They are e.g., railway wagons, ships, cars, crushers, bucket conveyors, cranes, electric arc furnaces and others. 


\subsection{The Bulkscan LMS511 flow monitor}

The Bulkscan LMS511 optical flow monitor is considered for the pipe conveyor, which enables non-contact and maintenance-free volumetric flow recording [1]. It uses multiple reflection technology for recording, which from the length of time that takes the laser beam to hit the surface and the belt speed determines the volumetric flow of material. This technology is independent of the bulk material properties and weather conditions. Figure 5 shows the Bulkscan LMS511.

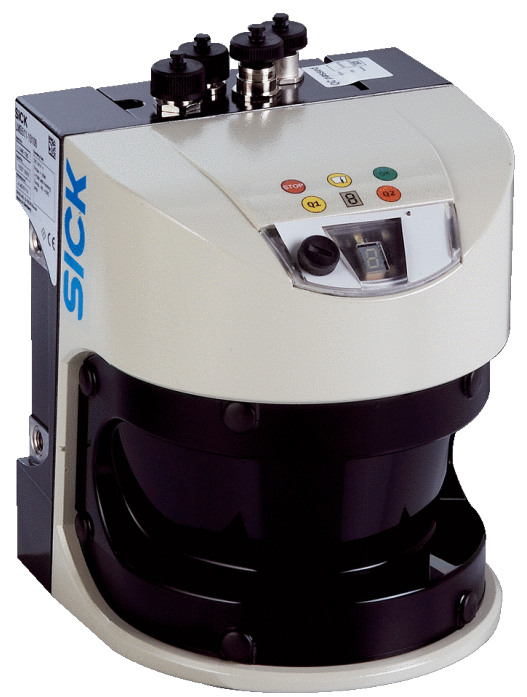

Figure 5: The Bulkscan LMS511 flow monitor [10]

\subsubsection{The advantages of the BulkScan LMS511}

- maximizing transport performance,

- maximizing the throughput of the conveyor,

- saving maintenance costs by preventing buckling of the conveyor belt,

- increasing the efficiency of transport of the belt by optimizing the load (integrated determination of the centre of gravity of the material on the belt).

- easy installation,

- minimum maintenance costs,

- increasing conveyor belt life,

- cost savings by minimizing energy consumption,

- wide range of operating temperatures,

- robust body made of special alloys,

- connecting to superior communication systems via Ethernet TCP / IP [10].

\subsubsection{Areas of application of BulkScan LMS511}

Other Bulkscan LMS511 application deployments include:

- monitoring of raw materials in the food production industry,

- monitoring of transport equipment for coal or ore transport,

- loading and bagging equipment,

- recording ash discharges in power plants,

- control of loading of means of transport e.g. cars, ships, railway wagons,

- measuring the volume of bulk materials in gravel pits and other operation facilities of the building materials industry,

- measurement of clinker weights in cement plants,

- volume monitoring of pneumatic components [10].

\section{Results}

\subsection{Alternative designs for mounting the Bulkscan LMS51 material flow monitor}

Five alternative methods of attachment with a technical outline have been proposed:

(i) rigid frame,

(ii) sliding beam

(iii) rigid frame with sliding bracket in 1 axis,

(iv) rigid frame with sliding crossbeam and sliding bracket in 1 axis,

(v) $1 / 2$ rigid frame with sliding crossbar in 1 axis and fixed bracket.

1. Rigid frame - this way of mounting the sensor consists of a rigid construction frame on which the sensor holder is fixed (Figure 6). The holder does not allow any adjusting movement of the sensor.

Advantages:

- simple production,

- easy assembly / disassembly

- easy maintenance,

- solid construction,

- there is no loosening of the frame parts.

Disadvantages:

- the frame is not flexible,

- without possibility of moving the holder with the sensor. 


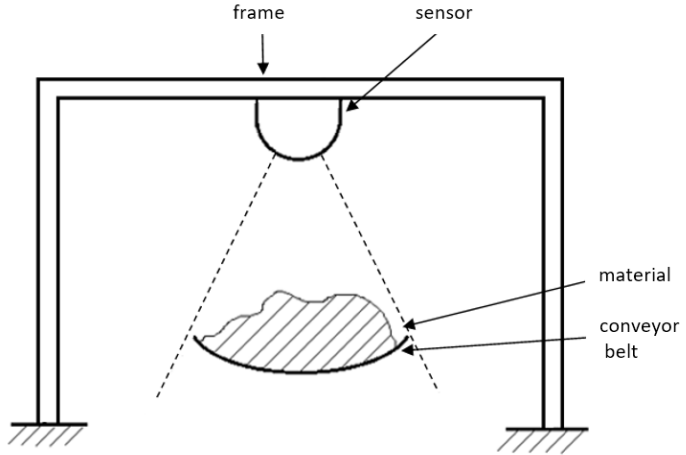

Figure 6: Rigid frame

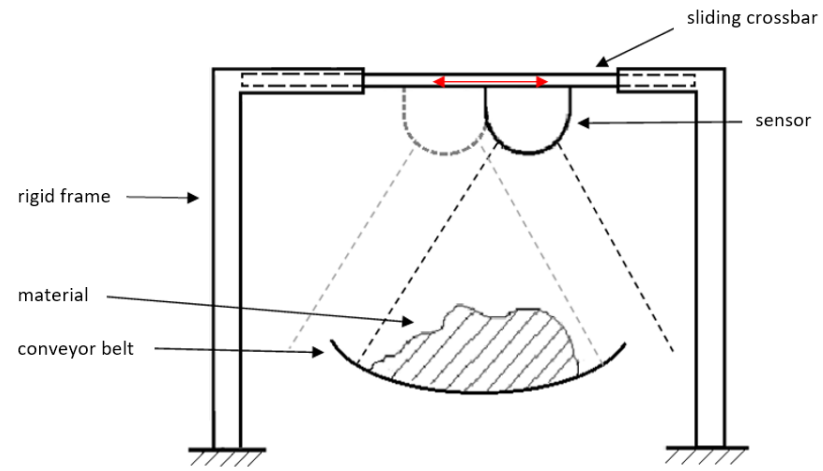

Figure 7: Sliding crossbar

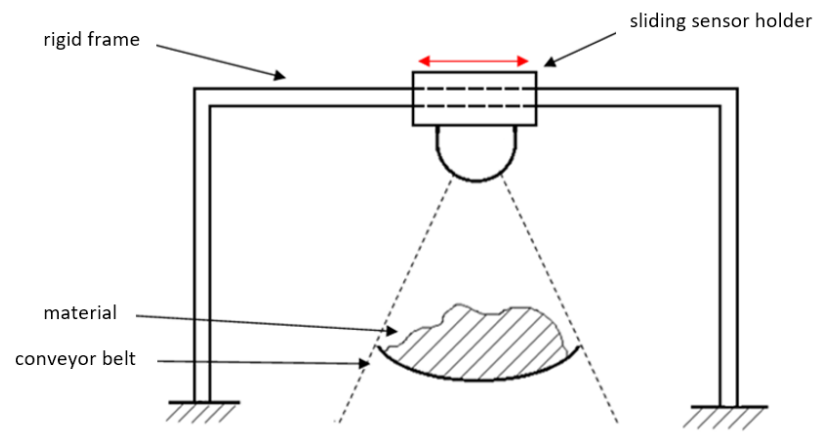

Figure 8: Rigid frame with sliding holder in 1 axis

2. Sliding crossbar - its specific feature is that the crossbar is located in the centre of the rigid frame, which, thanks to its openings on both sides, is able to move in 1 axis (Figure 7). A sensor holder that allows to scan material from different angles but also different widths of conveyor belts is fixed on the sliding element.

Advantages:

- can be used for different conveyor belt widths

- scanning material from different angles.

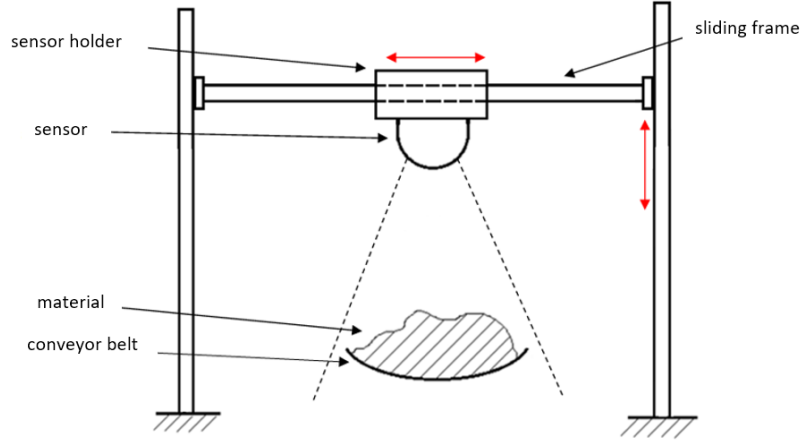

Figure 9: Rigid frame with sliding crossbar in 1 axis and a sliding bracket

Disadvantages:

- the moving part must be anchored when the scanning angle is changed,

- limited movement of the holder,

- manual handling.

3. Rigid frame with sliding bracket in 1 axis - a sensor holder is mounted on the rigid frame of the conveyor, which can move around its periphery in 1 axis and be anchored in the desired place (Figure 8). The mobility interface is larger than in the previous example in Figure 7, since it can also be attached to the extreme part of the conveyor structure frame.

Advantages:

- can be used for different conveyor belt widths,

- multi-angle scanning of material,

- sliding of the holder along the entire length of the frame,

- easy assembly and disassembly,

- easy maintenance and replacement of parts.

Disadvantages:

- risk of loosening of the holder,

- manual handling.

4. Rigid frame with 1-axis sliding beam and sliding bracket - the structure consists of a rigid frame, a sliding bracket laterally attached to the frame and a sensor bracket moving along the sliding beam (Figure 9). This whole design allows the sensor to scan in the desired height and angle. The disadvantage is the lower stability of the whole structure, since there is a risk of loosening of individual parts.

Advantages:

- possible adjustment of height and angle of sensing,

- easy handling, 
Table 1: Evaluation criteria of individual variants

\begin{tabular}{|c|c|c|c|c|c|}
\hline \multirow[t]{2}{*}{ Criteria } & \multicolumn{5}{|c|}{ Mounting suggestions for Bulkscan LMS511 } \\
\hline & $\begin{array}{l}\text { Fixed } \\
\text { frame }\end{array}$ & $\begin{array}{l}\text { Sliding } \\
\text { crossbar }\end{array}$ & $\begin{array}{l}\text { Rigid frame } \\
\text { with sliding } \\
\text { holder in } 1 \\
\text { axis }\end{array}$ & $\begin{array}{l}\text { Rigid frame with } \\
\text { sliding crossbar } \\
\text { and sliding } \\
\text { bracket in } 1 \text { axis }\end{array}$ & $\begin{array}{c}1 / 2 \text { rigid frame } \\
\text { with sliding } \\
\text { crossbar in } 1 \text { axis } \\
\text { and fixed bracket }\end{array}$ \\
\hline simple assembly / disassembly & $x$ & $x$ & $\mathrm{x}$ & & $\mathrm{x}$ \\
\hline sensing adjustability & & & $\mathrm{x}$ & $\mathrm{x}$ & \\
\hline stability of the structure & $x$ & $\mathrm{x}$ & $x$ & $x$ & $\mathrm{x}$ \\
\hline easy handling & $x$ & $x$ & $x$ & & \\
\hline
\end{tabular}

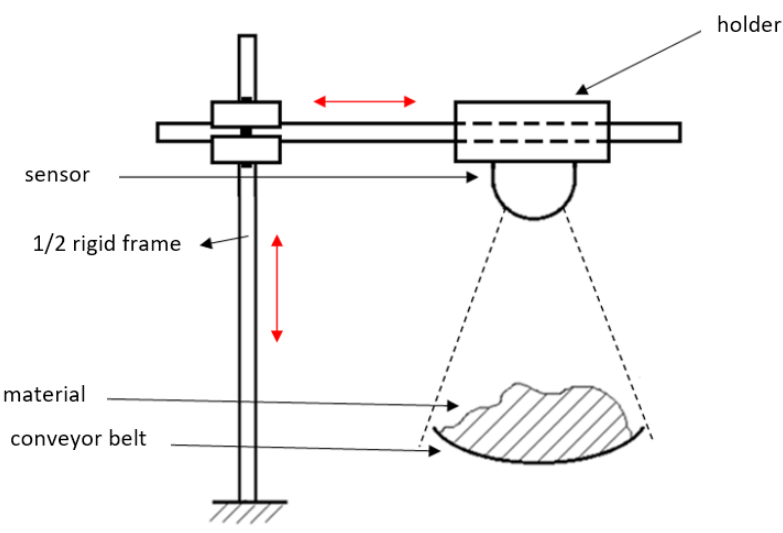

Figure 10: 1/2 Rigid frame with 1-axis sliding crossbar and fixed bracket

- easy assembly and disassembly,

- use for different conveyor belt widths,

- sliding the holder along the entire length of the frame.

Disadvantages:

- more difficult maintenance and replacement of parts,

- risk of loosening of the frame in case of stronger vibrations

- manual handling.

5. $1 / 2$ rigid frame with sliding crossbar in 1 axis and fixed bracket - this mounting design shows a rigid frame on which the angled bracket is fixed (Figure 10). Thanks to this, it is possible to move the crossbar in horizontal and vertical direction according to the material scanning needs on the conveyor belt. It is flexible, but there is a risk of loosening of the frame parts. The holder is firmly attached to the crossbeam.

Advantages:
- the possibility to adjust the height and angle of scanning,

- use for different conveyor belt widths.

Disadvantages:

- assembly and disassembly,

- maintenance and replacement of parts,

- risk of loosening of frame parts,

- limited movement of the holder,

- manual handling.

\subsection{Choosing the optimal mounting option for the Bulkscan LMS51 material flow monitor}

When selecting the optimal Bulkscan LMS511 material flow monitor mounting option, it is important to choose the right comparison method. Using the ratio index method, it is ascertained which proposed method of fixing is ideal taking into account the advantages and disadvantages of the variants. The ratio index method uses a direct classification of weights into groups that determine the individual weights of the selected criteria. The following criteria were chosen:

1. simple assembly / disassembly,

2. sensing adjustability;

3. stability of the structure,

4. easy handling.

The ' $x$ ' mark in Table 1 indicates that the proposal meets the criterion. Using the direct method of classifying weights into groups the individual weights of the criteria from Table 1 were determined. The assignment of weights to the criteria was as follows:

- a group of very important criteria $\geq 6$

- a group of moderately important criteria $\geq 4$

- a group of less important criteria $\geq 2$ 
Table 2: Standardized criteria values

\begin{tabular}{lcc}
\hline Criteria & Non-standard value $w_{j}$ & Standardized value $a_{j}$ \\
\hline simple assembly / disassembly & 2 & $2 / 14=0.14$ \\
sensing adjustability & 6 & $6 / 14=0.43$ \\
stability of the structure & 4 & $4 / 14=0.29$ \\
easy handling & 2 & $2 / 14=0.14$ \\
TOGETHER & 14 & 1 \\
\hline
\end{tabular}

Table 3: Calculation the overall utility of variant order by index method

\begin{tabular}{|c|c|c|c|c|c|c|c|c|c|c|c|}
\hline \multirow{3}{*}{$\begin{array}{l}\text { Criteria } \\
\\
\text { simple assembly / } \\
\text { disassembly }\end{array}$} & \multirow{3}{*}{$\begin{array}{l}a_{j} \\
\\
\\
0.14\end{array}$} & \multicolumn{10}{|c|}{ Mounting suggestions for Bulkscan LMS511 } \\
\hline & & \multicolumn{2}{|c|}{ Fixed frame } & \multicolumn{2}{|c|}{$\begin{array}{l}\text { Sliding } \\
\text { crossbar }\end{array}$} & \multicolumn{2}{|c|}{$\begin{array}{l}\text { Rigid frame with } \\
\text { sliding holder } \\
\text { in } 1 \text { axis }\end{array}$} & \multicolumn{2}{|c|}{$\begin{array}{c}\text { Rigid frame with } \\
\text { sliding crossbar and } \\
\text { sliding bracket in } 1 \text { axis }\end{array}$} & \multicolumn{2}{|c|}{$\begin{array}{c}1 / 2 \text { rigid frame with } \\
\text { sliding crossbar in } \\
1 \text { axis and fixed bracket }\end{array}$} \\
\hline & & 3 & 0.42 & 3 & 0.42 & 3 & 0.42 & 1 & 0.14 & 1 & 0.14 \\
\hline sensing adjustability & 0.43 & 1 & 0.43 & 1 & 0.43 & 3 & 1.29 & 3 & 1.29 & 3 & 1.29 \\
\hline $\begin{array}{l}\text { stability of the } \\
\text { structure }\end{array}$ & 0.29 & 3 & 0.87 & 3 & 0.87 & 3 & 0.87 & 3 & 0.87 & 1 & 0.29 \\
\hline easy handling & 0.14 & 3 & 0.42 & 3 & 0.42 & 3 & 0.42 & 1 & 0.14 & 1 & 0.14 \\
\hline TOGETHER & 1 & & 2.14 & & 2.14 & & 3 & & 2.44 & & 1.86 \\
\hline ORDER & & & & & 3. & & 1. & & 2. & & 4. \\
\hline
\end{tabular}

Independent experts then assigned weightings to the criteria in terms of importance. The normalized value $a_{j}$ was calculated from the assigned non-standard value $w_{j}$ divided by its total sum (Table 2). In Table 3, the calculated standardized values $a_{j}$ are multiplied by the partial utility determined by the direct approach by formula:

$$
\text { overall utility }=a_{j} \cdot \text { partial utility, }
$$

1 - does not meet the criterion, 3 - meets the criterion.

As can be seen from Table 3, the highest rated according to the ratio index method is the rigid frame with a sliding bracket in 1 axis.

\section{Discussion}

The optimal variant - rigid frame with sliding holder in 1 axis connects to the construction of the pipe conveyor above the conveyor belt (Figure 11). Installation of this variant is expected at VSH Turňa nad Bodvou, where the installation of new pipe conveyors is being prepared. Due to the selection of a particular conveyor, the construction dimensions were taken into account in the design. The mounting of the optical monitoring device is installed on the support structure of the conveyor before the conveyor belt is closed in the form of a pipe, in order to prevent overfilling or even clogging when transporting excessive quantities of conveyed material.
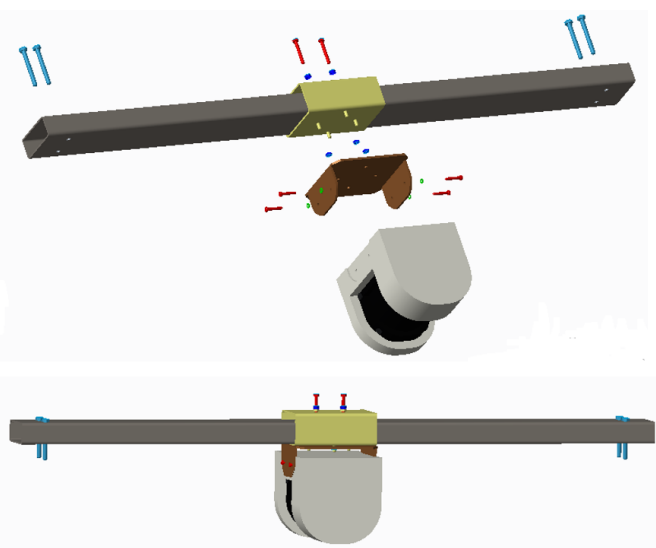

Figure 11: A 3D model of the proposed design variant

Table 4: Costs of implementation

\begin{tabular}{lcc}
\hline & Dimensions & Total costs \\
\hline Crossbeam material & $90 \times 40 \times 3[\mathrm{~mm}]$ & $€ 41.56$ \\
Holder material & $100 \times 60 \times 3[\mathrm{~mm}]$ & $€ 45.55$ \\
Welding and drilling operations & - & $€ 13 /$ hour \\
Assembly of components & - & $€ 15 /$ hour \\
\hline
\end{tabular}

A detailed breakdown of the costs of implementing the optimal variant is given in Table 4. 


\section{Conclusion}

Due to the increasingly sophisticated technology and development of transport systems, the emphasis is on the flawless transport of material on the conveyor belt. Pipe conveyors are no exception, because of their construction, length and mode of transport they form a complex transport system. They can withstand varying outdoor operating temperatures, adverse weather conditions or the transport of materials with different grain sizes.

The application of the selected optical interlocking device and the optimum attachment to the conveyor support structure results in a more rigorous inspection and detection of actual failures, as well as deficiencies in material transport. The proposed attachments of the interlocking device are recorded by sketches that provide information on the advantages and disadvantages. The result of using the evaluation method is a variant that best meets the established criteria for fixing the respective device to the supporting structure of the pipe conveyor.

Acknowledgement: This work is a part of the following projects: VEGA 1/0403/18, VEGA 1/0063/16, KEGA 012TUKE-4/2019, KEGA 013TUKE-4/2019, APVV SK-SRB-180053.

\section{References}

[1] Bulkscan_LMS511. Retrieved July 26, 2019, from www.sick.co $\mathrm{m} /$ media/docs/3/13/613/Product_information_Bulkscan_LMS5 11_en_IM0045613.pdf.
[2] Kulka J., Kopas M., Faltinova E., Mamntic M. \& Bigos P. (2016). Kinematic linkages in the hinged undercarriage of a mobile working machine, Scientific Journal of Silesian University of Technology-Series Transport. 91, 81-88. DOI: 10.20858/sjsutst.2016.91.8.

[3] Zeng F., Wu Q., Chu X. \& Yue Z. (2015). Measurement of bulk material flow based on laser scanning technology for the energy efficiency improvement of belt conveyors, Meas. J. Int. Meas. Confed. 75, 230-243. DOI:10.1016/j.measurement.2015.05.041.

[4] HeD., Pang Y. \& Lodewijks G. (2016). Speed control of belt conveyors during transient operation, Powder Technol. 301, 622-631. DOI:10.1016/j.powtec.2016.07.004.

[5] Wang S., GuoY.C., Li D.Y. \& Hu K. (2016). Research of lateral force of pipe conveyor belt's vertical transport section, Arch. Transp. 37, 67-75. DOI:10.5604/08669546.1203204.

[6] Aldrich C., Jemwa G.T., Van Dyk J.C., Keyser M.J. \& Van Heerden J.H.P. (2010). Online analysis of coal on a conveyor belt by use of machine vision and kernel methods, Int. J. Coal Prep. Util. 30, 331-348. DOI:10.1080/19392699.2010.517486.

[7] Marasová D., Taraba V., Grujic M., Fedorko G., Bindzár P. \& Husáková N. (2006). Pásová doprava.Košice, Slovakia: FBERG TU Košice.

[8] Fedorko G., Molnár V. \& Michalik P. (2013). Hadicové dopravníky /Pipe conveyors.Košice, Slovakia: ORTE, spol. s r.o.

[9] SICK Sensor Intelligence. Retrieved July 26, 2019, from ww w.sick.com/cz/cs/odvetvi/odpad-a-recyklace/spalovani-orga nickeho-odpadu-biomass-to-energy/dodani-a-skladovani-bio masy/rizeni-dopravnikoveho-pasu-a-sledovani-drtice-pro-spa lovani-organickeho-odpadu/c/p371224.

[10] SICK Sensor Intelligence.Retrieved July 26, 2019, from www.si ck.com/cz/cs/fluidni-senzorika/prutokomery/bulkscan-Ims5 11/c/g253553. 